\title{
Looking 'acceptably' feminine: A single case study of a female bodybuilder's use of steroids
}

\author{
Justin Kotzé*, Andrew Richardson, Georgios A. Antonopoulos \\ Teesside University, Borough Road, TS13BA, United Kingdom
}

\section{A R T I C L E I N F O}

\section{Article history:}

Received 10 June 2020

Received in revised form 24 August 2020

Accepted 31 August 2020

Available online $\mathrm{xxx}$

\section{Keywords:}

Bodily capital

Body image

Female bodybuilding

Hyper-conformity

Steroids

\begin{abstract}
A B S T R A C T
This article aims to shed some light on the motivations for and methods of female steroid consumption apropos broader changes in female body image ideals. Moreover, the study attempts to explore the connections between the competitive logic of liberal-postmodern consumer capitalism, 'competitive femininity' and steroid use. There is a growing consensus that an increasing number of women are consuming steroids, yet this phenomenon remains relatively under-researched and as such not much is known about this particular group of users. Utilising a single in-depth case study, this paper offers some additional insight gleaned from an ethnographic interview with a female bodybuilder who uses steroids. Her narrative elucidates some of the risks, harms and motivations for steroid consumption alongside broader changes in female body image ideals. Among the central findings, this paper highlights that the female bodybuilder is not resisting cultural norms but rather hyper-conforming to them by overidentifying with a hyper-idealised form of what constitutes 'acceptable femininity'. We conclude that steroid consumption retains a strong connection to the desire for aesthetic appeal and that both short and long-term motivations for using steroids are grounded in the drive for conformity. This has pertinent clinical implications for health professionals, particularly in relation to the efficacy of attempts to reduce steroid consumption by warning users of the potential adverse health effects.
\end{abstract}

(c) 2020 Elsevier Ltd. All rights reserved.

\section{Introduction}

Fitness, rather than health, has undoubtedly become the contemporary standard to be met in the twenty-first century (Bauman, 2012). The aesthetic dimension of the body now takes front-andcentre stage against the backdrop of the changing currency of bodily capital, as the body itself becomes a site of consumption (Kotzé \& Antonopoulos, 2019). Moreover, health psychologist Sarah Grogan, 2017Grogan (2017) points out that in the current milieu, physical attractiveness carries with it symbolic cues that predispose a sense of social competence. Indeed, "the firm, toned body is seen as representing success", a view mirrored in the almost ubiquitous stream of 'fitspiration' content flooding social media (Grogan, 2017Grogan, 2017: 11). In this context, where the fine-tuning of one's body remains for many the last vestige of control (Kotzé \& Antonopoulos, 2019 ), ultimate failure comes in the form of being perceived as overweight (Grogan, 2017). This pressure is borne by both men and women and some, in growing numbers, respond to this pressure by consuming body image drugs, among which steroids is probably

\footnotetext{
* Corresponding author.

E-mail address: j.kotze@tees.ac.uk (J. Kotzé).
}

the best-known (Kanayama et al., 2001 Kanayama, Pope, \& Hudson, 2001).

Anabolic-androgenic steroids (hereafter, steroids) are synthetic substances that simultaneously stimulate tissue building and skeletal muscle growth and the development of masculinising properties (Amsterdam et al., 2010Amsterdam, Opperhuizen, \& Hartgens, 2010; Wright et al., 2000Wright, Grogan, \& Hunter, 2000). Evidence suggests that the consumption of steroids has substantially increased over the last several decades (Huang \& Basaria, 2018), and that the most popular forms of steroids are among the most counterfeited image and performance-enhancing drugs (Hall \& Antonopoulos, 2016; Hall \& Antonopoulos, 2019). All evidence internationally (see, for example, Cole \& Mobley, 2005; Sagoe et al., 2014Sagoe, Molde, Andreassen, Torsheim, \& Pallesen, 2014; Henne \& Livingstone, 2019; Van de Ven et al., 2019) indicates that the majority of anabolic steroid users are male with the highest levels of use in those aged between 20-40 years of age. This has remained unchanged since the 1990s (Lenehan et al., 1996Lenehan, Bellis, \& McVeigh, 1996; Public Health Institute, 2017; Horwitz et al., 2018Horwitz, Andersen, \& Dalhoff, 2018). Although steroid use is more common amongst men, and the prevalence amongst women is more difficult to estimate (see, for instance, Kanayama et al., 2001), there is a growing consensus that an increasing number of women are consuming steroids (see Thiblin \& Petersson, 
2005; Skårberg et al., 2008Skårberg, Nyberg, \& Engström, 2008; Abrahin et al., 2017Abrahin, Souza, Corrêa de Sousa, Moura Santos, \& Bahrke, 2017; Huang \& Basaria, 2018; Henning \& Andreasson, 2019; see also O'Dea \& Cinelli, 2016). However, whilst it is acknowledged that more women are using steroids, not much is known about this group of users (Strauss et al., 1985Strauss, Liggett, \& Lanese, 1985; Korkia et al., 1996Korkia, Lenehan, \& McVeigh, 1996; Ip et al., 2010; Börjesson et al., 2016Börjesson, Gårevik, Dahl, Rane, \& Ekström, 2016). ${ }^{1}$ Research studies have found it particularly difficult to recruit female steroid users principally because they are much rarer than their male counterparts (Korkia et al., 1996; Ip et al., 2010; Börjesson et al., 2016).

The aim of this study is to shed some light on the motivations for and methods of female steroid consumption apropos broader changes in female body image ideals. Moreover, the study attempts to explore the connections between the competitive logic of liberal-postmodern consumer capitalism, 'competitive femininity' and steroid use. In studying phenomena of comparative rarity, Pearson and Hobbs, 2003Pearson and Hobbs (2003) demonstrate how a single exploratory case study can often yield useful insights. Indeed, the utility of single case study research has been welldocumented (see Maruna \& Matravers, 2007; Kotzé, 2019), and it is for this reason that it has been adopted here. In the pages that follow we present the findings of a single in-depth ethnographic interview with a female bodybuilder who we have called 'Lisa'. We do not, of course, claim that 'Lisa' is representative of all female bodybuilders, or that her consumption of steroids is typical of women in this sport. Instead, the findings presented here are of interest precisely because they contribute to a body of knowledge characterised by its scarcity (see Börjesson et al., 2016), and because they may have some analytical generalisability (Yin, 2009). That is to say that perhaps by exploring this one in-depth case we can begin to apply the insights gained to analogously broader contexts. Towards this end it is perhaps instructive to explore the wider context of female bodybuilding and steroid consumption. But first, let us offer an account of the methods and data used in this article.

\section{Methods and data}

Data presented in this article are the product of ongoing research on steroid use and trade in a locale in the Northeast of England with one of the highest rates of steroid use in the UK (see Public Health Institute, 2017). The primary research site has been a gym in which the use (and trade) of steroids is widespread. Data have also been collected at four fighting events, four bodybuilding competitions and two product promotion events in the area. Within the context of this ongoing research, we have interviewed - among others - 26 steroid users ( 25 males and 1 female). Steroid users attend specific venues - most notably gyms - regularly and in a disciplined fashion as part of their training regime and consumption patterns. Having joined a gym, we began regularly attending and, over time, formed relationships with fellow gym attendees who were steroid users and/or dealers. This made access particularly straightforward during the ethnography, where in many cases our initial participants introduced us to other users (Atkinson \& Flint, 2004).

Interviews were conducted as free-flowing conversations with participants on a series of occasions. For some of the interviews tape-recording was possible but for the vast majority this was impractical. This largely depended on the time/hour of the interview, the space in which the interview took place and the mood

\footnotetext{
${ }^{1}$ It is interesting to note that although data on the use of steroids collected from the Crime Survey for England and Wales (CSEW) are available, the Office for National Statistics does not hold more detailed information such as a gender breakdown (Home Office, 2016).
}

of the interviewee. We were also cautious because our past experiences conducting empirical criminological research have led us to believe that the interviewer-interviewee relationship, the interviewing process, and the breadth and quality of data collected, can significantly improve if a tape/digital recorder is avoided (see Rapley, 2001). Instead, we used notebooks either during or immediately after the interview had finished. A memorised interview guide was used during all of the interviews conducted as part of this research. This memorised interview guide covered a number of general topics including 'motivations for use', 'sources of merchandise', 'people involved in steroid trade' etc. For the current article, the single case study of a female steroid user, there were effectively no inclusion criteria: data from the only female participant was used. The 'interview-data-as-a-resource' tradition was used to reflect the interviewee's reality (Ryan \& Bernard, 2000; Seale, 1998) about the topic. Accounts from this interview were subjected to discussion and consensus between us. Powerful and vivid extract examples from the data were selected to highlight accounts put forward. The participant was not involved in the analytical process, which was the case for other participants who have taken part in the study.

Our study presents some limitations, which should be acknowledged at this stage. Firstly, during ethnographic research there can be no guarantee that the information given is a wholly neutral representation of the activities and actors; one needs to remember that accounts offered in an ethnographic study are consciously or unconsciously interpreted by the researcher. Moreover, the data are limited to what the participants have provided and what the researcher has observed, and perhaps they cannot easily be generalised to the broader steroid use scene. The account from the single female participant most certainly cannot be used to generalise to the whole female steroid using population. In relation to the interview with our female participant, (as is the case with the other participants in the overall project) one can never be absolutely certain about validity, although 'member checking' - the "process in which collected data is 'played back' to the informant to check for perceived accuracy and reactions" (Cho \& Trent, 2006) significantly contributed towards eliminating untruthful accounts.

\subsection{Ethics}

Ethical approval for the research was granted by our university's research ethics committee. Needless to say, consent forms were neither provided to nor signed by our participants because of the sensitive nature of the research. However, it should be mentioned that all participants were verbally informed about the purpose and nature of our research as well as their rights (as participants) as put forward by the 'Code of Ethics' of the British Society of Criminology (British Society of Criminology, 2015), including their right not to participate, to withdraw at any stage during the interview, and to have their identity protected at all stages of the research process and beyond.

\section{Female bodybuilding, steroids and 'resistance'}

Since the 1980s interest in female bodybuilding has grown significantly (Bunsell, 2013; Grogan et al., 2006Grogan, Shepherd, Evans, Wright, \& Hunter, 2006). This growing interest has spawned an array of competitive events, each with their own categories, regulations and requirements that are strictly monitored and to which women must conform if they want to compete (Grogan et al., 2006; Grogan, 2017). Alongside this increase in women's competitions we have seen an increase in female bodybuilders consuming steroids (Grogan et al., 2006). This is perhaps unsurprising because there is mounting evidence to suggest that not only is steroid use encour- 
aged in bodybuilding, but is deemed necessary to compete (Wright et al., 2001Wright, Grogan, \& Hunter, 2001). Indeed, Grogan et al., 2006Grogan et al. (2006) point out that steroids are so ingrained in the bodybuilding culture that 'natural bodybuilding' competitions have been set up specifically for competitors who choose not to take steroids. Accordingly, the argument can certainly be advanced - and we shall develop this a bit more in a moment - that the sport of competitive bodybuilding is deeply integrated into the ideological core of neoliberalism. Its participants demonstrate a deep commitment to the competitive individualism, immediate gratification and the cultivation of envy that reside right at the heart of neoliberalism and therefore conform to, rather than deviate from, its cultural values and central tenets.

There can be little doubt that steroids work in facilitating this hyper-conformity (Grogan et al., 2006; Kotzé \& Antonopoulos, 2019 ). However, there are a number of adverse effects that must be considered, particularly in light of the fact that women are more vulnerable to many of the negative effects of steroids (Ip et al., 2010). Among the most common negative effects identified by the literature are increased facial and body hair, deepening of the voice, reduced breast size, menstrual disturbances, clitoromegaly, and severe mood changes (Börjesson et al., 2016; Huang \& Basaria, 2018; Ip et al., 2010). It is also suggested that women tend to downplay long-term serious side-effects, often minimizing them in relation to the positive effects on their body image (Grogan et al., 2006; Wright et al., 2001). Indeed, Grogan et al., 2006Grogan et al. (2006) note that the adverse effects of most concern to women "were those that had a direct effect on body image and fertility". Yet despite such risk studies have found that female steroid users often report intentions to continue using (Huang \& Basaria, 2018; Ip et al., 2010), perhaps because the potential long-term health risks are outweighed by a desire to acquire the immediate aesthetic gains necessary for competition (Grogan, 2017).

This preference for prioritising short-term aesthetic gain over long-term health is emblematic of the capitalist injunction to eschew deferred gratification and enjoy now; quickly acquire the 'appropriately feminine' look required in order to increase the chances of winning competitive events (Grogan, 2017). It certainly casts doubt over discourses that position female bodybuilding as challenging or resisting mainstream cultural ideals (Grogan et al., 2004Grogan, Evans, Wright, \& Hunter, 2004). Nevertheless, these narratives of resistance still have a relatively strong presence in the literature on female bodybuilding, perhaps because bodybuilding and muscularity are often seen as inappropriate for women (Grogan et al., 2004; Grogan, 2017). Therefore "women who aim for a muscular physique are transgressing current Western cultural norms" (Grogan et al., 2004Grogan et al., 2004: 50). For some, female bodybuilders challenge the representation of women as physically weak and the common tendency to associate traits such as muscularity and strength with masculinity (ibid.). For others, positioning female bodybuilders as the "radical cutting edge of feminist resistance to cultural ideals" is a somewhat optimistic view (Grogan, 2017Grogan, 2017: 57). Indeed, rather than representing the hard kernel of resistance it is possible that female bodybuilding is simply "another way of persuading women to change their bodies in line with a cultural ideal that stresses the importance of avoiding fleshiness" (Grogan et al., 2004Grogan et al., 2004: 50).

This less optimistic view certainly accords with contemporary interpretations of body image which tend to position the muscular, toned and strong-looking body as the new aesthetic ideal (Grogan, 2017). It is within this context that Grogan, 2017Grogan (2017) argues that female bodybuilders are both resisting and complying with mainstream social pressures. They are simultaneously resisting cultural norms by becoming 'unacceptably' muscular and conforming to a narrow set of ideals determined by the bodybuilding community. This argument is certainly compelling. However, we would argue that female bodybuilders are not resisting cultural norms but rather hyper-conforming to them by over-identifying with a hyper-idealised form of what constitutes 'acceptable femininity'. This can be seen from the way in which female bodybuilders dedicate themselves to the production of a bodily aesthetic that conforms to a tightly regulated and commercially defined view of femininity; athletic but not skinny, toned but not ripped, muscular but not 'huge' (Grogan et al., 2004). Far from resisting cultural norms by becoming 'unacceptably' muscular, female bodybuilding is deeply connected to notions of bodily obsession and vanity in ways that reflect "tendencies and vulnerabilities found in the broader gendered social world" (Probert et al., 2007Probert, Palmer, \& Leberman, 2007: 286). Therefore, the 'unacceptably' muscular aesthetic which Grogan, 2017Grogan (2017) identifies as the source of resistance is precisely the socio-symbolic display of conformity.

This revision must be viewed in the context of recent developments in idealised forms of body image. That is to say that bodybuilders are not contesting the dominant slender ideal precisely because this ideal is arguably no longer dominant. Indeed, Grogan, 2017Grogan (2017) points out that a desire for a waifish, thin-looking body has given way to a new aesthetic ideal that favours the muscular, worked-out, and strong-looking body. Accordingly, the act of building the body up rather than scaling it down does not constitute resistance, as Grogan et al., 2004Grogan et al. (2004) suggest, but rather conformity precisely because this is the new feminine norm. Within the context of competitive female bodybuilding this norm is hyper-idealised. Competitors are required to over-identify with this new aesthetic injunction and in doing so display a hyper-conformity to a highly commercialised and tightly regulated conception of the 'acceptable' feminine body image. In this way, the act of building the body up is undertaken precisely to be more competitively feminine, to adhere more closely to a set of predefined specifications so as to increase their chances of winning events (Grogan, 2017). As we have seen, it is within this context that steroid use is not considered deviant but rather expected and necessary for competition (Wright et al., 2001).

This ascription to what we call 'competitive femininity' is intimately connected to the competitive logic of liberal-postmodern consumer capitalism. Indeed, accounts of female bodybuilders often present data that reveals this but rarely makes the connection explicit. Nevertheless, even a cursory scan reveals narratives steeped in the drive for symbolic capital, the cultivation of envy in others, competitive individualism, immediate gratification and short-termism (see for example, Grogan et al., 2006; Wright et al., 2001; Probert et al., 2007). This hyper-conformative competitive femininity is therefore in no way antagonistic to mainstream cultural norms and values. Rather, as has been found with male steroid users (Kotzé \& Antonopoulos, 2019 ), the opposite is true in as much as many demonstrate a deep commitment to the commercially defined and highly competitive ideal of an 'appropriately' feminine body image. Certainly, 'Lisa's' route into bodybuilding did not begin from a desire to challenge cultural perceptions of women but precisely to conform to them. Indeed, like many other women who are more likely to exercise for aesthetic reasons rather than for health (Grogan, 2017), 'Lisa' began exercising because "I was getting a bit chubby". Then after gradually introducing weights into what was predominantly a cardio based routine, 'Lisa' progressed through quite a few gyms before arriving at what she called a 'bodybuilding gym'.

\section{Bulking up and looking good}

'Lisa' is now a competitive bodybuilder in her mid-twenties and has a very muscular and athletic physique. On the subject of body image ideals 'Lisa' was quite candid about her own experience: 
When I was sixteen I wanted to be as thin as possible. I wanted thin legs, I wanted thin arms, I was like, what, eight stone, at one point, and I thought, at the time, I looked amazing. I looked like a model. Now when I look back, I'm like 'I look ill' and over that time when fitness came into my life, I then wanted big legs.

For 'Lisa', this experience was emblematic of broader rapid changes in body image ideals. She expressed that as little as four years ago:

Bodybuilders were too far. Now, oh God, they all want to look like that, they need to look like that, they need to have these capped delts, they need to have this or that, and it's they need to look a certain way. It's no longer extreme, now that's the norm.

This accords with Grogan's ([Grogan,2017]2017) contention that the muscular, worked-out, and strong-looking body is now the new feminine bodily aesthetic to aspire to. However, it is interesting to consider this change not as a cultural U-turn per se but rather as a process of sculpting a more detailed configuration of the previous ideal. This is a process of 'fleshing out' by adding fine and toned detail to the slender silhouette of previous iterations of the ideal female bodily aesthetic. This modified preference for the toned and hard-looking body is not only considered appropriately feminine (Grogan et al., 2004; Grogan, 2017), but accords with the 21st century's obsession with aesthetic perfectibility. This is demonstrated beautifully in the world of cinema where CGI (Computer-Generated Imagery) is used with increasing fervour to achieve "full believability through an erasure of flaws" (Manon, 2016Manon, 2016: 193). The problem, however, is that CG cinema gives the impression that aesthetic mastery is possible yet, as Manon, 2016Manon (2016) points out, "this poses a problem for the human subject, for whom mastery is impossible and perpetual dissatisfaction is constitutive".

The same is true of course of the filters used on social media sites such as Instagram and Snapchat, which are used to erase flaws to such an extent that the content often possesses an excessive naturality. Since this constitutes a supra-natural aesthetic unobtainable without external aid, it renders the revered bodily form pre-eminently unnatural (Kotzé \& Antonopoulos, 2019). However, naturalness is no longer the currency of bodily capital, what matters is the symbolic capital derived from achieving the required aesthetic. This carries with it intense social pressure to capture flattering selfies worthy of that social media post (Grogan, 2017). Indeed, 'Lisa' commented that:

People don't realise it when they do it but their insecurities come out all over Instagram, all over Facebook because they can't train without taking a video or taking an after-selfie, or they have to tell their full workout of that day, what they ate, what they've done, and it's almost like they need people's approval in order for that to mean something.

Here social media operates as a surrogate big Other verifying the act (Kotzé, 2020). This is captured neatly in a popular phrase that 'Lisa' recalled, "If you didn't take a selfie, did you even train"? Interestingly, 'Lisa' acknowledges that the inherent vacuity of the process is irrelevant so long as one obtains the requisite symbolic capital; "It doesn't matter how fake it is, as long as its going to get those likes". This is reflected in the ability to buy likes, "so basically now they don't even need to do the hard work, just go and buy it and you can get likes". This is particularly interesting in the context of body image precisely because it functions in a similar fashion to steroid consumption. That is to say, this cyber-consumption is undertaken to circumvent deferred gratification and secure the quick fix thereby accelerating one's 'Instafame' (see also Richardson et al., 2019Richardson, Dixon, \& Kean, 2019). This virtualisation of aesthetic pleasure has arguably heightened the drive to attain a bodily aesthetic that not only aligns with but maximises a positive sense of self (Probert et al., 2007). Indeed, 'Lisa' noted how it used to be about "sculpting their body into something that made themselves feel better. Now it's still to make them feel better but more for a different reason, it's almost like they do it just to get Instafamous".

The motivation for steroid use has long been linked to aesthetic appeal (Ip et al., 2010; Kanayama et al., 2001; O’Dea \& Cinelli, 2016). With the increased permeation of social media this motivation has arguably been increased significantly. 'Lisa' felt that steroids are being consumed to:

Look like the Instagram models look like because if you look like that fitness model, that Instagram model, if you do all the photo shoots and stuff, people are going to notice you more. They're going to like you more...The more you compete, the more pictures you get in a bikini, the more attention you get for it. So, they're going to take them [steroids] for appearance and the majority of them will take them not knowing the real effects that they have or the long-lasting ones.

This resonated with 'Lisa's' own experience of consuming steroids. Her initial motivations were based upon a desire to transform the body as quickly as possible into an aesthetically pleasing commodity to be enjoyed; that is, to render the body itself as a site of pleasurable consumption (Kotzé \& Antonopoulos, 2019).

I wanted to get a six-pack and I thought that was the quickest way. I went for the quick fix. Yes, so in the start, it definitely was that quick fix. I wanted to look like this. This was going to get me there quicker. I'm going to take that.

'Lisa' went on to note that, “I knew I didn't need to take them to get the muscle but I wanted it quick - so obviously anabolic steroids, any performance-enhancing drugs, they speed up the process". However, this early experience was laden with a number of risks that were exacerbated by a lack of knowledge, as 'Lisa' explains:

I started with the Black Mamba, which I then stopped taking because I felt ill on them, probably didn't take them the way I was supposed to take them. . .then I was introduced to Winstrol, which I took on and off for a year, didn't really take it properly the way you were meant to take it. I didn't really understand cycles, et cetera, this was when I was in the very early stages of bodybuilding.

Beyond various internet 'bibles' that profess to offer unbiased information, much of the information regarding steroid consumption and its effects are gleaned by beginners from those deemed more experienced and knowledgeable. However, as Wright et al., 2001Wright et al. (2001) point out, these are often "the bigger people in the gyms who think they know what they are telling you is right”. This certainly accords with 'Lisa's' account as she described a number of experiences with what Hall et al., 2016Hall, Grogan, and Gough (2016)) call 'lay expertise': "I was going by word of mouth by someone who actually really didn't know what they were talking about at all". In preparation for her first bodybuilding competition 'Lisa' told us that:

I took Prop [Testosterone Propionate] and Anavar, my coach was an idiot, and introduced me to a whole load of other drugs that I didn't actually need to take. I trusted him, and I had, again going back to what I should look like, I had this in my head and I need to look like this so I need to take these drugs, so I then started taking Anavar, I was on 20 milligrams in the end.

Whilst polypharmacy is a common practice amongst steroid users (Gruber \& Pope, 2000; Hall \& Antonopoulos, 2016), it has been suggested that women are less likely to 'stack' - taking more than one steroid at a time - and more likely to 'pyramid' - gradually increasing the dosage and then tapering down - than men (Ip et al., 
2010). However, this was not reflective of 'Lisa's' experience who recalled her whole stack apropos her preparation for competition:

Proviron, I was on 50 milligrams. Arimidex ... I was on 10 milligrams of that every other day, T3s [Triiodothyronine] should never have touched them, I can't even remember how much of that I was on, that was horrific, absolutely horrific. I was still on Clen [Clenbuterol] at the same time as well, and instead of cycling all of that I took that every day for months on end, so again I wasn't introduced - I knew I should cycle, but I didn't cycle because I listened to someone else, who I thought knew everything because funnily enough Instagram and Facebook had told me, so I'd never actually met him in real life, he was my coach whom I found through Instagram.

The effects of this misuse (Grogan et al., 2006) were significant as 'Lisa' expressed that she "actually ended up quite unwell, both mentally and physically. Mentally I was body dysmorphia to hell, physically I was drained and tired".

There was, however, also a pastoral element to 'steroid coaching' evident in 'Lisa's' narrative. Indeed, there were those she "actually did know, and actually were interested in keeping me healthy". For example, 'Lisa' recalled how:

I started learning off of one of the other personal trainers, who was known as the Godfather of Steroids, he pretty much knew how to cycle things, what was good, what was bad, basically I was introduced to Clen, wasn't sure how to take it so he told me how to take it.

Reference was also made to another coach who "basically, step by step took me through how to do it, how to be safe about it". This pastoral element is similar to the 'social supply' evidenced by Antonopoulos and Hall, 2016Antonopoulos and Hall (2016) whereby knowledge and product transactions take place devoid of commercial motivations (see also Richardson \& Antonopoulos, 2019 ). In the absence of easily accessible forms of credible knowledge this element of pastoral support is salient because, as 'Lisa' notes, when she first started "I didn't even know anything about it [steroids], at that stage I was completely innocent to everything". More to the point, in recounting her use of Anavar, Proviron, Arimidex, T3s, Clenbuterol and Primobolan, 'Lisa' noted how "pretty much all of them were oral bar the Primobolan which is an injection". This is a crucial point because it has been well documented that steroid tablets can be highly toxic (Author and Hall, 2016). Moreover, oral forms of steroids are removed more slowly by the liver which means, all things considered, injecting steroids is actually the safer method of consumption (Wright et al., 2001). Yet, as demonstrated by 'Lisa', and supported by the literature, women are more likely to consume steroids orally than men (Börjesson et al., 2016; Ip et al., 2010).

'Steroid coaching' is evidently part of the bodybuilding culture but telling the good from the bad can be challenging, particularly for newcomers. Whilst our case does not necessarily support Börjesson et al., 2016Börjesson et al. (2016) contention that the onset of female steroid use is triggered by men in close relationships, it does suggest that 'steroid coaches' tend to be men. Furthermore, whilst 'Lisa's' boyfriend did not trigger her use of steroids, he does serve as her coach from whom she draws knowledge:

I still learn off of people now. The likes of my boyfriend's way more clued up than I am, so basically anything he says, I sit and I take it all in, his word is not going to be gospel but when you take everybody's point of view, you make up your own point of view.

In keeping with views expressed in the wider literature (e.g. Grogan et al., 2006), 'Lisa' held a relatively positive view of steroids and perhaps also displayed a tendency to underestimate the potential negative effects: "I don't have any issues with steroids as long as they're used appropriately. I just think people need to understand them more but if you don't understand them don't take them". There was also no indication that 'Lisa' intended to stop using steroids despite previous negative experiences and potential future health risks. Whilst the motivations for using steroids can be complex and person-specific (Wright et al., 2001), these are often rooted in the drive to boost one's aesthetic appeal and competitive edge. As we have seen, this is far from representing the green shoots of resistance to dominant cultural ideals. Instead, such motivations demonstrate a deep commitment to the competitive logic of liberal-postmodern consumer capitalism.

Against this cultural backdrop it may be more instructive to view bodybuilding not as a sub-culture (Grogan et al., 2006), but as an exacerbated microcosm whose participants over-identify with and hyper-conform to capitalism's dominant cultural injunctions. Indeed, the almost ubiquitous presence of steroids in bodybuilding perhaps indicates the extent to which the sport is imbedded within mainstream consumer capitalism. Steroids are not used as a means of resisting cultural injunctions but precisely to facilitate one's conformity to them. This is evident throughout much of the literature and throughout 'Lisa's' narrative. What is interesting is that this drive for conformity is evident in both short and long-term motivations. As already mentioned, her initial motivations were rooted in a desire for immediate gratification and the cultivation of envy in others; mirroring the dominant injunction to eschew long-term considerations in favour of short-term gains. Long-term motivations, however, were rooted in a desire to maintain or perhaps even exceed the desired aesthetic and competitive edge: "generally it was the quick fix I went for but now my reasons are about distance. Now, its for the specific effects that it can offer me, accompanying what I do in the gym and with my nutritionist".

Representations of female bodybuilding as resistance must certainly be read much more critically, particularly in light of the considerable constraints imposed by the bodybuilding community regarding acceptable degrees of muscularity (Grogan et al., 2004). Indeed, as we have tried to argue here, it is perhaps more fruitful to view aspects of female bodybuilding as a means of hyper-conforming to mainstream cultural ideals. This is perhaps further demonstrated by research findings which suggest that competitive female bodybuilders demonstrate greater body dissatisfaction compared to recreational weight-lifters (Goldfield, 2009). Additional weight is added when these findings are viewed in conjunction with those that connect female bodybuilding with bodily obsession and vanity (Probert et al., 2007). For 'Lisa', this seemed to resonate quite strongly:

I think people who don't compete in the sport or don't really take much interest in participating in the sport, they probably live a happier life in terms of they don't really care what they look like as much. Whereas you get into bodybuilding to get yourself into better shape, but once you get to that better shape that you thought you wanted, you end up, no this isn't good enough, I don't like that bit, I don't like this, that bit is holding too much fat, that's not strong enough and you just sit and you pick and you pick and you pick, because you're always going to be your worst critic because you can't see what other people can see.

This constant picking at perceived defects or flaws is certainly characteristic of body dysmorphic disorder, or more specifically the subtype muscle dysmorphia (Smith et al., 2016Smith, Rutty, \& Olrich, 2016). Although often discussed as a psychiatric disorder, we could perhaps consider this phenomenon much more broadly in relation to a sense of subjective lack which consumer capitalism both cultivates and promises, yet always fails, to alleviate 
(McGowan, 2016). Indeed, it could be argued that the long-term health risks associated with steroid consumption are outweighed by the short-term aesthetic gain, precisely because the attainment of bodily improvement promises to help alleviate this sense of subjective lack. If this is the case, then it has serious clinical implications. At the very least it suggests that we may need to rethink prevention strategies that are designed to reduce steroid consumption by warning users of the potential adverse health effects. Whilst space precludes further analysis of this here, future research could be directed towards unpicking this in more detail.

\section{Conclusion}

The aesthetic dimension of bodily capital has obtained a new position of salience in the 21st century. Our obsession with aesthetic perfectibility and the virtualisation of aesthetic pleasure has placed increased pressure on the need to maximise one's body image. In a milieu where poor body image signals the ultimate failure, it is perhaps unsurprising to find that the consumption of image and performance-enhancing drugs such as steroids is increasing. Whilst often associated with men, there is a growing consensus that female steroid consumption is growing. This growth has arguably occurred in tandem with an increase in women's participation in competitive bodybuilding, a sport within which steroid use is both encouraged and deemed necessary to compete. The ubiquitous presence of steroids in bodybuilding perhaps highlights the extent to which the sport is deeply integrated into the ideological circuitry of neoliberalism. Indeed, its participants demonstrate a deep commitment to liberal-postmodern consumer capitalism's core values and tenets; competitive individualism, the cultivation of envy, immediate gratification and short-termism.

Nothing in our case study of 'Lisa' supported the view that female bodybuilding represented a form of resistance to mainstream cultural ideals. Instead, her narrative seemed to support the view that bodybuilding should not be viewed as a sub-culture, but rather as an exacerbated microcosm whose participants overidentify with a hyper-idealised form of what now constitutes 'acceptable' femininity. As the wider literature suggests, and as our case study has highlighted, the new feminine norm is not the slender silhouette of yesteryear but rather the worked-out, muscular and strong-looking body. This more detailed configuration of the ideal female bodily aesthetic resonated with 'Lisa' and arguably stimulated her consumption of steroids, both as a means of attaining it quickly and maintaining it once achieved. Yet, as demonstrated here, there are a number of significant risks that accompany steroid consumption; many of which may be exacerbated by placing too much stock in the lay expertise of 'steroid coaches'. However, there was also a more pastoral element to 'steroid coaching' evident in 'Lisa's' narrative which is important to highlight here because of the role it played in reducing some of the risks associated with her methods of consumption. Indeed, this may prove all the more important because 'Lisa' gave no indication that she intended to stop using steroids despite previous negative experiences and potential future health risks.

There remains comparably little research on female steroid users and there is certainly a need for additional empirical and theoretical work in this area; work that could have significant clinical implications. Previous research has shown that there are several adverse effects experienced by female steroid users such as menstrual irregularities, deepening of the voice, and clitoral enlargement (Abrahin et al., 2017). However, steroid users are reluctant to talk about steroid use and their negative effects to 'outsiders'. Advice is very rarely - if at all -sought from medical professionals (Pope et al., 2004Pope, Kanayama, Ionescu-Pioggia, \& Hudson, 2004), which makes steroid users a ‘hard-to-reach' group for these professionals, and female users may be an even 'harderto-reach' group. As anti-doping policy has shifted and become more punitive, the distribution of steroids has moved away from dealers embedded in a sporting 'sub-culture' to a range of 'non-experts', which leaves users at greater risk (see Fincoeur et al., 2014Fincoeur, van de Ven, \& Mulrooney, 2014). The Internet provides abundant opportunities for such non-expert suppliers active in the steroid market, offering mechanisms used to target those users who lack contacts in a local gym culture (Antonopoulos \& Hall, 2016). Obtaining a better understanding of females' motivations to use steroids, and their preferred methods of consumption, is essential in preventing harm and mitigating the range of negative experiences of female users. However, the findings of this article suggest that the efficacy of attempts by the healthcare profession to reduce steroid consumption by warning users of the potential adverse health effects should be reconsidered. More research should be directed towards exploring the link between body dysmorphic disorders and the subjective lack cultivated by liberal-postmodern consumer capitalism. If more is known about this harmful symbiosis, then perhaps more targeted clinical interventions can be mobilised to greater effect.

\section{Declaration of Competing Interest}

The authors report no declarations of interest.

\section{Acknowledgement}

Early stages of the ongoing study were partly supported financially by the European Commission (Award reference: HOME/2011/ISEC/AG/FINEC/4000002221).

\section{References}

Abrahin, O., Souza, N., Corrêa de Sousa, E., Moura Santos, A., \& Bahrke, M. S. (2017) Anabolic-Androgenic steroid use among Brazilian women: An exploratory investigation. Journal of Substance Use, 22(3), 246-252.

Amsterdam, J., Opperhuizen, A., \& Hartgens, F. (2010). Adverse health effects of anabolic-androgenic steroids. Regulatory Toxicology and Pharmacology, 57(1), 117-123.

Antonopoulos, G. A., \& Hall, A. (2016). Gain With no Pain': Anabolic-Androgenic Steroids Trafficking in the UK. European Journal of Criminology, 13(6), 696-713.

Atkinson, R., \& Flint, J. (2004). Snowball sampling. In M. S. Lewis-Beck, A. Bryman, \& T. Futing Liao (Eds.), The sage encyclopaedia of social science research methods (vol 1) (pp. 1043-1044). Thousand Oaks, Ca: Sage.

Bauman, Z. (2012). Liquid modernity. Cambridge: Polity.

Börjesson, A., Gårevik, N., Dahl, M., Rane, A., \& Ekström, L. (2016). Recruitment to doping and help-seeking behaviour of eight AAS users. Substance Abuse Treatment, Prevention, and Policy, 11(11) http://dx.doi.org/10.1186/s13011016-0056-3

British Society of Criminology. (2015). Statement of ethics Available online at:. http://britsoccrim.org/new/?q=node/22

Bunsell, T. (2013). Strong and hard women. London: Routledge.

Cho, J., \& Trent, A. (2006). Validity in qualitative research revisited. Qualitative Research, 6(3), 319-340

Cole, C. L., \& Mobley, A. (2005). American steroids: Using race and gender. Journal of Sport and Social Issues, 29(1), 3-8.

Fincoeur, B., van de Ven, K., \& Mulrooney, K. J. D. (2014). The symbiotic evolution of anti-doping and supply chains of doping substances. Trends in Organised Crime http://dx.doi.org/10.1007/s12117-014-9235-7

Goldfield, G. (2009). Body image, disordered eating and anabolic steroid use in female bodybuilders. Eating Disorders, 17(3), 200-210.

Grogan, S. (2017). Body image: Understanding body dissatisfaction in men, women, and children (3rd edition). London: Routledge.

Grogan, S., Evans, R., Wright, S., \& Hunter, G. (2004). Femininity and muscularity Journal of Gender Studies, 13(1), 49-61.

Grogan, S., Shepherd, S., Evans, R., Wright, S., \& Hunter, G. (2006). Experiences of anabolic steroid use. Journal of Health Psychology, 11(6), 845-856.

Gruber, A., \& Pope, H. (2000). Psychiatric and medical effects of anabolic-androgenic steroid use in women. Psychotherapy and Psychosomatics, 69(1), 19-26.

Hall, M., Grogan, S., \& Gough, B. (2016). Bodybuilders' accounts of synthol use: The construction of lay expertise online. Journal of Health Psychology, 21(9), 1939-1948 
Hall, A., \& Antonopoulos, G. A. (2016). Fake Meds Online: The Internet and the Transnational Market in Illicit Pharmaceuticals. London: Palgrave Macmillan.

Hall, A., \& Antonopoulos, G. A. (2019). The (Online) Supply of Illicit Lifestyle Medicines: A Criminological Study. In K. Van de Ven, K. J. D. Mulrooney, \& J. McVeigh (Eds.), Human Enhancement Drugs. London: Routledge.

Henne, K., \& Livingstone, B. (2019). More than unnatural masculinity. In K. Van de Ven, K. J. D. Mulrooney, \& J. McVeigh (Eds.), Human enhancement drugs (pp. 13-26). London: Routledge.

Henning, A., \& Andreasson, J. (2019). “Yay, another lady starting a log!”: Women's fitness doping and the gendered space of an online doping forum. Communication E Sport, http://dx.doi.org/10.1177/2167479519896326

Home Office. (2016). Drug misuse: Findings from 2015/2016 crime survey for England and Wales (2nd edition). London: Home Office.

Horwitz, H., Andersen, J. T., \& Dalhoff, K. P. (2018). Health consequences of androgenic anabolic steroid use. Journal of Internal Medicine, http://dx.doi.org/ $10.1111 /$ joim. 12850

Huang, G., \& Basaria, S. (2018). Do anabolic-androgenic steroids have performance-enhancing effects in female athletes? Molecular and Cellular Endocrinology, 464, 56-64.

Ip, E., Barnett, M., Tenerowicz, M., Kim, J., Wei, H., \& Perry, P. (2010). Women, and anabolic steroids. Clinical Journal of Sport Medicine, 20(6), 475-481.

Kanayama, G., Pope, H., \& Hudson, J. (2001). ‘Body Image’ Drugs: A Growing Psychosomatic Problem. Psychotherapy and Psychosomatics, 70(2), 61-65.

Kotzé, J. (2019). The Myth of the "Crime Decline": Exploring Change and Continuity in Crime and Harm. London: Routledge.

Kotzé, J. (2020). The commodification of abstinence. In S. Hall, T. Kuldova, \& M. Horsley (Eds.), Crime, Harm and Consumerism. London: Routledge.

Kotzé, J., \& Antonopoulos, G. A. (2019). Boosting bodily capital: maintaining masculinity, aesthetic pleasure and instrumental utility through the consumption of steroids. Journal of Consumer Culture, http://dx.doi.org/10. $1177 / 1469540519846196$

Korkia, P., Lenehan, P., \& McVeigh, J. (1996). Non-medical use of androgens among women. The Journal of Performance Enhancing Drugs, 1(2), 71-76.

Lenehan, P., Bellis, M., \& McVeigh, J. (1996). A study of anabolic steroid use in the North West of England. The Journal of Performance Enhancing Drugs, 1(2), 57-70.

Manon, H. (2016). beyond the beyond: CGI and the anxiety of overperfection. In M. Flisfeder, \& L. Willis (Eds.), Žižek and media studies: A reader. Basingstoke: Palgrave Macmillan.

Maruna, S., \& Matravers, A. (2007). N=1: Criminology and the person. Theoretical Criminology, 11(4), 427-442.

McGowan, T. (2016). Capitalism and desire: The psychic cost of free markets. New York: Columbia University Press.

O'Dea, J., \& Cinelli, R. (2016). Use of drugs to change appearance in girls and female adolescents. In M. Hall, S. Grogan, \& B. Gough (Eds.), Chemically modified bodies: The use of diverse substances for appearance enhancement. London: Palgrave Macmillan.

Pearson, G., \& Hobbs, D. (2003). King pin? A case study of a middle market drug broker. The Howard Journal, 42(4), 335-347.

Pope, H. G., Kanayama, G., Ionescu-Pioggia, M., \& Hudson, J. I. (2004). Anabolic steroid users' attitudes towards physicians. Addiction, 99(9), 1189-1194.

Probert, A., Palmer, F., \& Leberman, S. (2007). The fine line: An insight into 'Risky' practices of male and female competitive bodybuilders. Annals of Leisure Research, 10(3-4), 272-290.
Public Health Institute. (2017). Image and performance enhancing drugs. Liverpool: Public Health Institute, John Moores University.

Rapley, T. J. (2001). The art(fullness) of open-ended interviewing. Qualitative Research, 1(3), 303-323.

Richardson, A., Dixon, K., \& Kean, J. (2019). Superheroes? Image and Performance Enhancing Drug (IPED) use within the UK, Social Media and Gym Culture. Journal of Forensic and Legal Medicine, 64, 28-30.

Ryan, G., \& Bernard, H. R. (2000). Data management and analysis methods. In N. K. Denzin, \& Y. S. Lincoln (Eds.), Handbook of qualitative research. Thousand Oaks: Sage.

Sagoe, D., Molde, H., Andreassen, C. S., Torsheim, T., \& Pallesen, S. (2014). The global epidemiology of anabolic-androgenic steroid use: A meta-analysis and meta-regression analysis. Annals of Epidemiology, 24, 383-398.

Seale, C. (1998). Researching society and culture. London: Sage.

Skårberg, K., Nyberg, F., \& Engström, I. (2008). The development of multiple drug use among anabolic-androgenic steroid users: Six subjective case reports. Substance Abuse Treatment, Prevention, and Policy, 3(24) http://dx.doi.org/10. 1186/1747-597X-3-24

Smith, D., Rutty, M., \& Olrich, T. (2016). Muscle dysmorphia and anabolic-androgenic steroid use. In M. Hall, S. Grogan, \& B. Gough (Eds.), Chemically modified bodies: The use of diverse substances for appearance enhancement. London: Palgrave Macmillan.

Strauss, R., Liggett, M., \& Lanese, R. (1985). Steroid use and perceived effects in ten weight-trained women athletes. JAMA, 253, 2871-2873.

Thiblin, I., \& Petersson, A. (2005). Pharmacoepidemiology of anabolic androgenic steroids: A review. Fundamental and Clinical Pharmacology, 19(1), 27-44.

Van de Ven, K., Mulrooney, K. J. D., \& McVeigh, J. (Eds.). (2019). Human enhancement drugs. London: Routledge.

Wright, S., Grogan, S., \& Hunter, G. (2000). Motivations for anabolic steroid use among bodybuilders. Journal of Health Psychology, 5(4), 566-571.

Wright, S., Grogan, S., \& Hunter, G. (2001). Body-builder's attitudes towards steroid use. Drugs: Education, Prevention and Policy, 8(1), 91-95.

Yin, R. (2009). Case study research: Design and methods (4th edition). Thousand Oaks: Sage.

Justin Kotzé is a Senior Lecturer in Criminology and Criminal Justice at Teesside University, UK. He was awarded his $\mathrm{PhD}$ in 2016 and has previously published work on the historical sublimation of violence; the consumption of steroids as a means of boosting bodily capital; and the commodification of abstinence. He is also the author of The Myth of the 'Crime Decline': Exploring Change and Continuity in Crime and Harm (Routledge, 2019) and co-editor of Zemiology: Reconnecting Crime and Social Harm (Palgrave, 2018).

Andrew Richardson is a PhD Student at Teesside University in the School of Social Sciences Humanities and Law. His research interests cover; image and performance enhancing drugs, health inequalities, sedentary lifestyles and esports. He has recently published work entitled Änabolic-androgenic steroids (AAS) users on AAS use: Negative effects, 'code of silence', and implications for forensic and medical professionals.

Georgios A. Antonopoulos is professor of criminology at Teesside University, UK. His research interests include 'organised crime' and illegal markets. He is the editor-inchief of Trends in Organised Crime. 